\title{
Imagem, Memória e Informação: um tripé para o documento fotográfico
}

\author{
Miriam Paula Manini
}

\begin{abstract}
Possui Bacharelado e Licenciatura em Ciências Sociais pela UNESP/Araraquara, 1987; Mestrado em Multimeios pela UNICAMP, 1993; Especialização em Conservação e Preservação Fotográfica pelo Centro de Conservação e Preservação Fotográfica da FUNARTE, 1994; Especialização em Organização de Arquivos pelo Instituto de Estudos Brasileiros da USP, 1998; e Doutorado em Ciências da Comunicação (Área: Ciência da Informação) pela ECA/USP, 2002. Desde 2002, é professora do Curso de Arquivologia e do Programa de Pós-Graduação em Ciência da Informação da Universidade de Brasília, atuando principalmente com os seguintes temas: Memória e Informação, Cinema e Arquivo, Leitura e Indexação de Imagens, Análise Documentária de Fotografias, Conservação de Documentos em geral. É líder do Grupo de Pesquisa Imagem, Memória e Informação; membro do Grupo de Pesquisa e Extensão da Câmara dos Deputados Vídeo Digital na Câmara dos Deputados: a relação entre preservação digital versus memória institucional e membro do Grupo de Pesquisa em Preservação de Bens Culturais.
\end{abstract}

\section{Resumo}

Este texto é resultado de reflexões em torno de três eixos conceituais que orbitam em torno da fotografia: imagem, memória e informação, aqui chamados de tripé fotográfico. Dividido - não de maneira absoluta - também em três partes, quais sejam Fotografia como Imagem, Fotografia como Memória e Fotografia como Informação, o trabalho reúne esta tríade que conforma o documento fotográfico presente não só em arquivos, mas em outras instituições reconhecidas como lugares de cultura e memória. Em Fotografia como Imagem, a abordagem gira em torno dos signos constituintes e observáveis na imagem fotográfica a partir de análises orquestradas por Charles Sanders Peirce, apresentadas por Philippe Dubois, e passando também pelo crivo semiológico de Roland Barthes. Em Fotografia como Memória, trabalha-se o aspecto do registro perpetuador do referente, resultante da abordagem acima, que torna a fotografia um objeto do passado e, portanto, um objeto de memória, fazedor de lembranças, provocador de rememorações e ponto inicial de narrativas memorialistas. Em Fotografia como Informação, voltamos ao tema da representação e da análise documentária de fotografias, ferramenta da Ciência da Informação e da Documentação no acesso e compartilhamento de memórias.

Palavras-chave: Fotografia; imagem; memória; informação.

\section{Abstract}

This paper is the result of reflections around three main concepts that revolve around photography, image, memory and information, here called photographic tripod. Divided - absolutely not also in three parts, which are Photography as Image, Photography as Memory and Photography as Information, the work session this triad that makes up the photographic document not only present in archives, but in other institutions recognized as places of culture and memory. In Photography as Image the approach revolves around the constituent signs and observable in the photographic image from analysis orchestrated by Charles Sanders Peirce, presented by Philippe Dubois, and also passing through the semiological sieve of Roland Barthes. In Photography as Memory, working on the aspect of the record concerning the perpetrator, resulting from the above approach, which makes the photograph an object from the past and, therefore, an object of memory, maker of memories, recollections and provocative starting point for narratives. In Photography as Information we return to the issue of the representation and analysis of documentary photographs, tools of Information Science and Documentation in accessing and sharing memories.

Keywords: Photography; image; memory; information. 


\section{Imagem, Memória e Informação: \\ um tripé para o documento fotográfico}

Introdução

Assim como Barthes (1984) postula o "isto foi"1, Benjamin (1987) refere-se à fotografia como "imagem do passado", e a ela imputa o caráter aurático ${ }^{2}$, pela capacidade - entre outras - de suspender num objeto um recorte de espaço/tempo. Essa possibilidade da fotografia - que é, na verdade, essência de sua existência - é que a torna um objeto de memória.

A memória é algo a que chegamos após um processo de abandono da presença e/ou da existência de alguém, de alguma coisa ou de algum fato. Ela nos mostra quem somos, pela "aquisição, formação, conservação e evocação de informações" (IZQUIERDO, 2002, p. 9).

Parece fúnebre pensar que a fotografia é uma imagem viva e, ao mesmo tempo, morta: oferece o referente tal e qual, fustigado, porém - e morto - pelo instante do clique. Metáfora semelhante foi proposta por Cartier-Bresson ${ }^{3}$, que comparava o disparador da máquina a uma arma de fogo, com a qual se fere mortalmente o objeto fotografado, caça e caçador num embate silencioso, só quebrado pelo tiro. A mortalha fotossensível eterniza, contudo, o referente, relegando-o a um lugar de memória.
Estando a fotografia em tal locus de memória, é necessário alinhar esta imagem técnica aos seus ancestrais e também aos seus descendentes, num processo de meta-memória. Imagem, pintura rupestre, caverna, ídolos, símbolos, adoração do sagrado; gravura; pintura barroca, realista, expressionista, impressionista, cubista, dadaísta; litografia, fotografia, cinema, história-em-quadrinhos, fotonovela, televisão, vídeo, ícones, holograma, imagem digital: o olhar também precisou evoluir para conseguir abranger, varrer, decupar, interpretar e produzir sentido ao longo da história das imagens, especialmente com relação àquelas que se tornaram documentos.

\section{Fotografia como imagem}

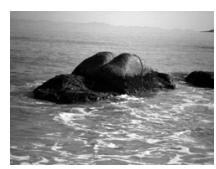

Manini. Florianópolis, 2008.

Servindo-se da teoria peirceana dos signos, Dubois (1986) propõe uma análise semiótica da fotografia que caminha por estas três concepções: a fotografia como espelho do real (Ícone), a fotografia como prova do real (Índice) e a fotografia como transformação do real (Símbolo).

Barthes (1984, p. 115) afirma que, se algo foi fotografado é porque "isto foi", ainda que se tenha representado a cena (a fotografia e seu análogo).

2 Coberto ou continente de aura (trata-se, a princípio, de um neologismo que já vem sendo usado há algum tempo nesta acepção).

3 Henry Cartier-Bresson (1908-2004), fotógrafo francês de grande expressão e importância no século XX. Cunhou - e, mais que isso, realizou - o conceito de momento decisivo, segundo o qual a fotografia é resultado de espera para o melhor disparo, no instante ideal, para registro mais desejável pelo fotógrafo. 
Dubois coloca que, com a fotografia, já não se pode pensar a imagem fora do ato que a torna possível. Então, é impossível dissociar o conteúdo da imagem de sua contextualização histórica (em se tratando, especialmente, de um documento fotográfico), assim como é importante associar a forma (técnica) da fotografia à sua expressão.

O ato fotográfico não é só o momento da tomada, o clique do fotógrafo, mas a produção da imagem, a recepção e/ou a contemplação da mesma. Assim sendo, esta abordagem da recepção de que fala Dubois é fundamental para analisar o documento fotográfico não só sob a perspectiva da Semiótica, mas também pelo da Ciência da Informação.

Dubois se propõe a fazer um apanhado histórico das ideias que foram construídas a respeito da relação da imagem fotográfica com o referente nela representado. Para tanto, articula três abordagens possíveis da imagem fotográfica, baseadas na teoria peirceana dos signos.

Em primeiro lugar Dubois coloca a fotografia como ícone, ou seja, a fotografia como espelho do real, recorte espaçotemporal, analogia referencial. Esta categoria se utiliza do discurso da mímesis e coloca a fotografia numa relação de semelhança com o referente; é uma representação na medida em que se cobre de verdade e de autenticidade. A fotografia icônica é vista como um análogo do real, como observou Barthes (1984, p. 15, p. 114 e segs., p. 127-129).

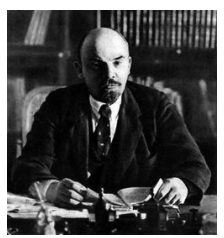

V. I. Lênin em fotografia impressa, em seu gabinete no Kremlin. Moscou, outubro de 1918. http:// www.stel.ru/museum/soviet_state. htm, acesso em 02/4/2011.
Neste exemplo para o ícone, o registro de Lênin em seu escritório espelha a realidade deste personagem no momento da tomada: é um recorte de espaço-tempo e a imagem é análoga ao real fotografado.

Já a segunda categoria proposta por Dubois é a fotografia indicial. Trata-se da fotografia como marca do real, marca no sentido de traço, de prova, de sinal da realidade. Esta categoria dá à fotografia a qualidade de ser vestígio, marca, registro de uma realidade. Inseparável de sua existência referencial, ela testemunha: trata-se de uma representação por conexão física com o referente ${ }^{4}$.

A fotografia como índice utiliza o discurso da referência para fazer ver a realidade inegável de uma imagem, apesar da consciência dos inúmeros códigos envolvidos em sua construção.

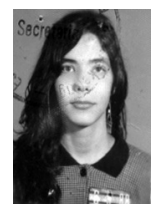

Nome: Fernanda D'Umbra. Postada em 15/9/2005. < http://semgelo.zip.net/ arch2005-09-01_2005-09-30.html > , acesso em 02/4/2011.

$\mathrm{Na}$ acepção utilizada ao longo deste trabalho, qualquer fotografia é um índice. Este retrato $3 \times 4 \mathrm{~cm}$ indica que esta é Fernanda: é a marca, um traço, uma prova da realidade da estudante naquele momento; há uma conexão física entre a fotografada e a sua imagem.

A fotografia como símbolo é uma outra categoria: trata-se da fotografia como transformação do real. A fotografia como símbolo é aquela sobre a qual recaíram elementos tais como ideologia, cultura, sociedade, estética e até mesmo técnica (um conjunto de códigos); é uma representação por convenção. $\mathrm{O}$ discurso de que se utiliza

4 Ela é mais fatual que as outras categorias, mas não menos válida no sentido histórico. 
é o do código e o da desconstrução, já que está ligada à ideia de transposição, de análise, de interpretação e de transformação do real, uma codificação cultural da imagem.

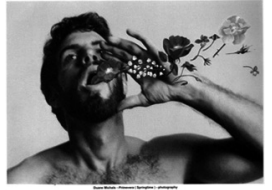

Primavera. Duane Michals. $<$ http://laurakingimages. blogspot.com/2009/11/ duane-michals-one-my-favorite. html > , acesso em 02/4/2011.

O exemplo para o símbolo é uma fotomontagem, na qual um homem solta flores pela boca, numa evidente transformação da realidade através da fabricação de um referente ou da criação de um efeito que se faz de referente. Sobre esta imagem recaiu o elemento técnica: uma reconstrução da composição da fotografia.

O índice refere-se à realidade, à dimensão ontológica da fotografia, à sua essência, absolutamente pertencente à indicialidade. $\mathrm{O}$ ícone e o símbolo remetem a dimensões diferentes - e distintas entre si -, mais da ordem do representacional e, por isso, ilimitado: é indício ${ }^{5}$ e não índice.

Barthes (1984) tornou absoluta a questão da mímesis fotográfica com a sua ideia do análogo: a imagem não é o real, mas seu análogo perfeito, uma mensagem sem código. Entretanto, a grande contribuição de Barthes é justamente a de ter trazido a concepção da gênese automática da mensagem sem código que é, para ele, a fotografia.

\section{Fotografia como memória}

Eu não dei por esta mudança, tão simples, tão certa, tão fácil: em que espelho ficou perdida a minha face? Poema Retrato, de Cecília Meireles.

A memória é, por si só, uma espécie de imagem; certamente não uma fotografia, mas um desenho, que esboçamos na mente, de maneira tímida e que pode, sim, completarse na visualização de uma fotografia; e esta viria como um fio de meada cinematográfica, impondo um verdadeiro filme às nossas lembranças.

Como indaga Ricoeur (2007, p. 61), seria a lembrança uma imagem que fazemos do passado? A fotografia, no caso, sendo exatamente uma imagem que se faz do passado, é um objeto que pressupõe rememoração.

A consciência íntima que temos da passagem de tempo acaba sendo abalada e certificada pelo testemunho do objeto fotográfico. O efeito da imagem fotográfica sobre a memória é devastador. No exercício historiográfico, quando confrontamos dados históricos textuais com fotografias podemos corrigir a memória escrita e reformular aquilo que já se conhecia.

A definição mais antiga de fotografia após o significado etimológico escrita com a luz - diz ser ela um recorte de espaço da realidade num determinado momento (tempo). Este objeto que carrega um fato, coisa ou pessoa do passado - e cada clique tem seu passado imediatamente criado insere-se instantaneamente na categoria de objeto de memória.

Pessoas, grupos, sociedades, povos inteiros poderão reconhecer numa fotografia um referente aurático de sua própria história. $\mathrm{Na}$ fotografia doméstica, é a memória familiar; na fotografia do mundo do trabalho, é a memória institucional; no fotojornalismo, é a memória social e política; na fotografia documental, é a memória histórica.

Nada marca melhor a aura-memória da fotografia do que o "isto foi". Na esteira dos teóricos da modernidade, Barthes (1984 e

5 Índice: prova cabal; Indício: sinal, prova circunstancial. 
1990) sempre apontou que o sentido da imagem é o fotografado, o objeto fotográfico, estando o fotógrafo (como operador) em segundo plano, e o meio fotográfico também: esta é a fotografia documental. O objeto é o referente real; o "isto foi", ou seja, algo da ordem da memória.

A fotografia, no momento em que nasce, já é um objeto do passado.

A relação que a imagem fotográfica indicial mantém com o referente é marcada pelos princípios da conexão física (principalmente espacial, mas, por vezes, também temporal $\left.{ }^{6}\right)$, da singularidade, da designação, do testemunho e da memória. As noções de sentido e existência colocadas por Dubois para a fotografia em geral são também importantes para o caso do documento fotográfico. A fotografia enquanto índice afirma a existência de seu referente, mas não diz coisa alguma sobre ele, a não ser aquilo que é dado aos olhos ver; seu significado não é priorizado.

A primeira e a mais importante consequência teórica da categoria indicial é que a fotografia, tomada em seu princípio de marca, é sempre necessariamente singular. Também por sua gênese, a fotografia testemunha ontologicamente aquilo que dá a ver: a fotografia certifica, ratifica e autentica (e isto não tem a ver com o seu significado ou sua autenticidade probatória).

Já a imagem fotográfica icônica mantém com o referente uma relação de mímesis, de representação e analogia, marcada pelo fator semelhança. A fotografia como ícone relaciona seu referente com realidades semelhantes e exige do profissional da informação ou do receptor um repertório mais largo.
A imagem fotográfica simbólica, por sua vez, amplia ainda mais a atuação - e a liberdade - de quem a analisa ou observa, pois mantém com o referente uma relação de convenção, estabelecida através de conexões filosóficas, culturais, ideológicas, sociais, etc.

Finalizando a questão da produção ou gênese do ato fotográfico, é bom lembrar que antes e depois dele, do momento da tomada em si, existiu uma realidade que conduziu à tomada e, depois dela, outros acontecimentos - especialmente culturais terão ou continuarão tendo lugar. Estas são questões levantadas por Philippe Dubois e reforçam o aspecto temporal da fotografia.

Schaeffer (1996), por sua vez, trata da imagem fotográfica mais como signo de recepção que de emissão, lançando a ideia do ícone indicial. Ele inicia, de fato, sua defesa do ícone indicial definindo os limites da imagem fotográfica: aquém estaria o fotograma e além estaria a radiografia. Enquanto o fotograma é impressão direta, contato com o suporte, contorno do referente, a radiografia é projeção, trespasse, reflexo. É entre estes dois pólos que se movimenta o índice fotográfico "na função analógica de sua realização icônica" (SCHAEFFER, 1996, p. 55).

Ao analisar mais de perto o documento fotográfico sob o prisma da Semiótica, nesta perspectiva de Schaeffer, chegamos a algumas observações. Schaeffer (1996) trata do signo fotográfico, mas fala da fotografia enquanto registro, enquanto conceito, enquanto procedimento; portanto, não limita sua análise a um tipo ou outro de fotografia. No nosso caso, há um recorte: pensamos sempre na fotografia enquanto documento ${ }^{7}$, pertencente a um acervo de imagens, detentora de uma informação - espera-se -

\footnotetext{
6 Ver exemplo da fotografia da garrafa, mais adiante.

7 Lembrando que o Índice é uma categoria que dá à fotografia a qualidade de ser vestígio, marca, registro de uma realidade. Inseparável de sua existência referencial, ela testemunha: trata-se de uma representação por conexão física com o referente.
} 
devidamente contextualizada. A qualidade de ser um documento, entretanto, não tira dessa fotografia o caráter de procedimento, o caráter de ser, enfim, uma fotografia simplesmente.

Quando buscamos ou observamos uma fotografia, é primeiramente a imagem em si que nos interessa e, secundariamente, seu modo de emissão, sua autoria, etc. Entretanto, não só interessa seu conteúdo, mas a forma como este conteúdo é expresso: de alguma maneira é a este conjunto que observamos quando olhamos para uma fotografia.

Para buscar com mais exatidão os vestígios icônicos e indiciais da fotografia, Schaeffer escolhe a melhor definição do que esta venha a ser: imagem do tempo. Verifica-se a verdade desta afirmação ao analisar o registro que a fotografia faz do tempo: ela só o faz através de uma extensão espacial. Usamos como exemplo a fotografia de uma garrafa com seu conteúdo pela metade; deduzimos que em momento anterior à tomada fotográfica, aquela quantidade ausente foi consumida, derrubada ou despejada: o espaço vazio da garrafa indica o tempo passado e o consumo da bebida. Neste caso, o ícone fotográfico (garrafa pela metade da fotografia a seguir) induz uma conclusão: torna-se o índice perfeito do tempo (a conclusão, a marca, o sinal da passagem de tempo).

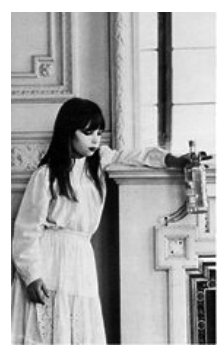

PLISSART, Marie-Françoise. Droit de regards. Paris: Minuit, 1985, p. 77. (Roman-photo).
Nesta fotografia, retirada de uma narrativa fotográfica sequencial, a garrafa na mão da menina aparece sem parte de seu conteúdo: dentro da história, esta relação de tempo passado e tempo presente é muito importante; esta fotografia narra quem esteve ali (alguém que tem por hábito beber) antes (tempo passado).

O ponto alto, entretanto, da contribuição de Schaeffer é o quadro que resumimos a seguir, sem, porém, esgotar as análises possíveis em torno dele. O quadro mostra as oito estratégias comunicacionais $\mathrm{da}$ imagem, ou seja, protocolo de experiência, traço, testemunho, descrição, rememoração, recordação, mostração e apresentação.

Schaeffer modalizou as combinatórias entre Tempo e Espaço, Indicialidade e Iconicidade e Entidades e Estados de Fato. Enquanto a Indicialidade e a Iconicidade têm a ver com a natureza do Representamen (o significante), e Tempo e Espaço se referem ao Interpretante (o significado), Entidades e Estados de Fato são distinções sugeridas pelo Objeto (o referente) ${ }^{8}$.

Se tomarmos a fotografia de Lênin (algumas páginas acima) para introduzir nesta grade de análise, sendo esta fotografia um exemplo de ícone, então a imagem de Lênin seria da ordem da recordação e da rememoração (em termos de tempo) e da apresentação e da mostração (em termos de espaço). A recordação e a rememoração são estados reflexivos em que se coloca o receptor: há uma garantia de reconhecimento temporal, de memória. A apresentação e a mostração dão ênfase à coisa que é mostrada: o recorte espacial é apresentado.

\footnotetext{
8 Lembrando que um signo é um significante ou representamen tomando o lugar de um referente ou objeto através de uma relação que estabelece um significado ou interpretante (Peirce, 1999).
} 


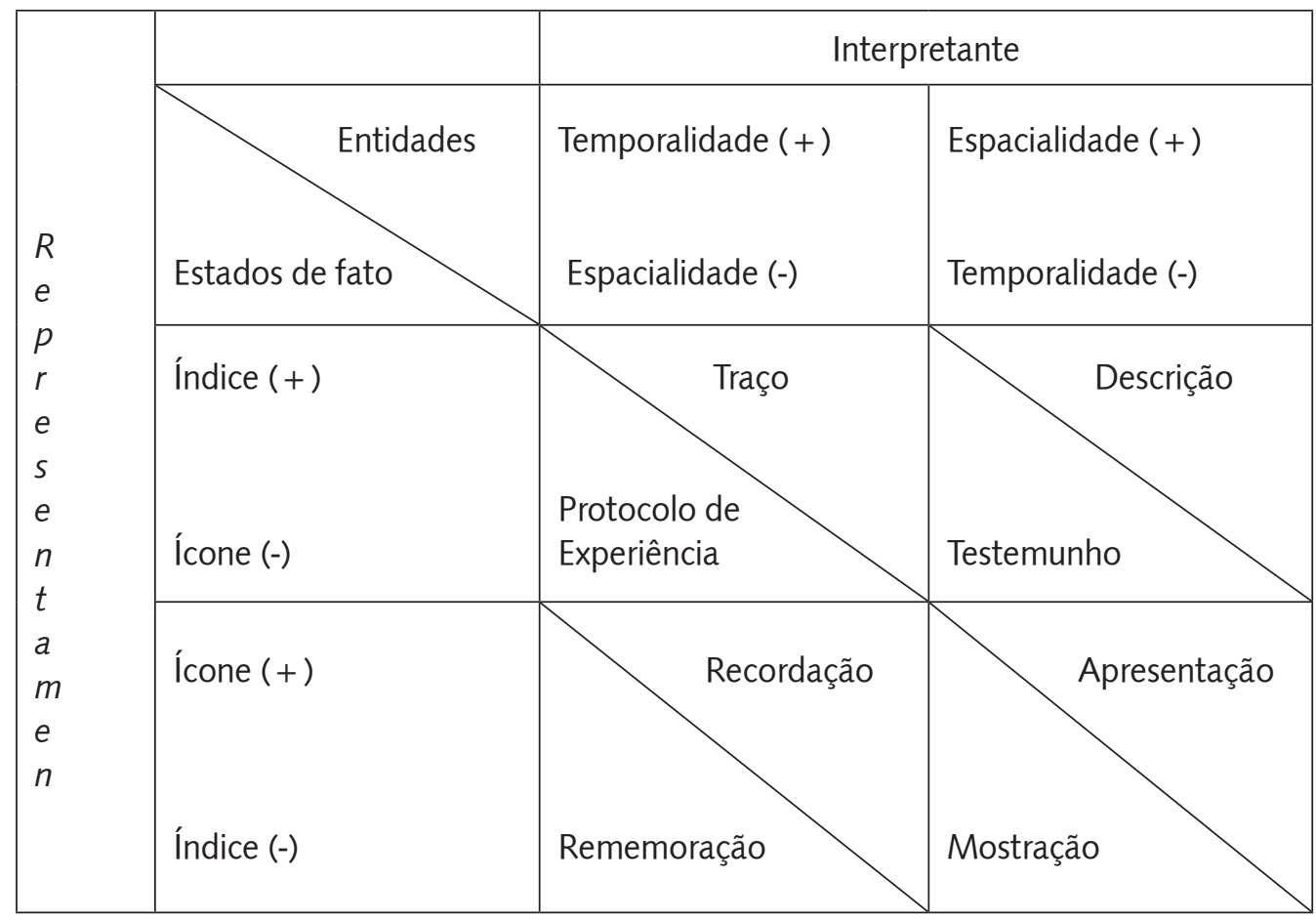

Fonte: Schaeffer, 1996, p. 66.

A moça da fotografia $3 \times 4 \mathrm{~cm}$ (algumas páginas acima), no papel de índice, estaria na categoria de traço e de protocolo de experiência (em termos temporais) e de descrição e testemunho (em termos espaciais). O traço e o protocolo de experiência servem como uma prova, através da fixação do tempo, enquanto descrição e testemunho são da ordem de um análogo espacial.

O índice fotográfico está mais relacionado ao que Schaeffer chama de protocolo de experiência, traço, testemunho e descrição (onde se localiza a informação fotográfica), enquanto o ícone fotográfico se refere mais à rememoração, à recordação, à mostração e à apresentação (lugares da mensagem fotográfica). Há mais a presença de temporalidade no traço, no protocolo de experiência, na recordação e na rememoração, ao passo que à espacialidade estão mais ligados a descrição, o testemunho, a apresentação e a mostração.
O documento fotográfico pode pretender imitar a realidade (ícone) e pode até ambicionar transformá-la (símbolo); entretanto, ele é muito mais testemunha da realidade (índice), registro de seu referente, com o qual mantém uma contiguidade física. Esta noção de contiguidade, ainda que suplantada pela questão do tempo que respira entre o ato fotográfico e a transformação do resultado - a imagem - em documento, investe, contudo, à fotografia o caráter de registro histórico, ou seja, de objeto de memória.

\section{Fotografia como informação}

Qué es la historia sin registro? Qué es la historia sin memoria? Quién la cuenta, quién la inventa? Quién la olvida, quién la borra? Memória, Grupo Erreway

Na tentativa de buscar uma melhor forma de tratar as informações contidas 
em documentos fotográficos sempre nos deparamos com outros estudos que declaram a dificuldade notória em tratar deste assunto com acurácia. Uma recuperação eficaz depende de uma indexação inteligente, permeada de estratégias e esmerada em amplificar não a quantidade, mas a qualidade do atendimento às necessidade informacionais do usuário de imagens fotográficas.

A intensidade da fome de fotografias de um pesquisador frente a um "prato" de imagens é proporcional à dificuldade que encontra em se alimentar: munido dos talheres de sua necessidade informacional, seleciona do cardápio aquilo que lhe parece apetitoso e nutritivo; muitas vezes, entretanto, fica sem saber se há maiores e melhores delícias naquele bistrô. Quando nos debruçamos em navegação nas janelas da Internet, mesmo que encontremos uma imagem procurada, ficamos sem saber se há outras, melhores (no sentido técnico e também informacional), impossíveis, entretanto, de serem recuperadas através dos dados por nós fornecidos.

Quando a imagem migra para o domínio do código e perde sua presença, seu aqui e agora, submetida às operações de cálculo e modelização, o que está em jogo não é apenas uma mudança de suporte ou de regime semiótico, mas a substituição do par Olho-Natureza pelo Cérebro-Informação. [...] a imagem não traz mais consigo a duração do olhar: a operação do olho bloqueia a operação da memória que acumula imagens (velha e persistente concepção). (GUIMARÃES, 2002, p. 153 e 158).

Não se trata apenas do não-objeto fotográfico, mas da capacidade de transformar a coisa dada em informação e, daí, em conhecimento. Buckland (1991) explora os níveis informação como coisa, informação como processo e informação como conhecimento. A partir de suas observações, podemos aplicar ao documento fotográfico uma abordagem semelhante, baseada na leitura que se faz da fotografia.

Para a Ciência da Informação interessa o significado e o contexto da imagem fotográfica. Portanto, o documento fotográfico precisa passar pelo crivo leitor de produção de sentidos - através do uso de métodos e técnicas existentes que abarque, também, a localização da imagem fotografada no tempo, no espaço e no organismo pulsante que é o acervo fotográfico enquanto repositório institucional de documentos e memória.

[...] os testemunhos sobre o passado oferecidos pelas imagens são de valor real, suplementando, bem como apoiando, as evidências dos documentos escritos. É verdade que, especialmente no caso da história dos acontecimentos elas freqüentemente dizem aos historiadores que conhecem os documentos algo que essencialmente eles já sabiam. Entretanto, mesmo nestes casos, as imagens têm algo a acrescentar. Elas oferecem acesso a aspectos do passado que outras fontes não alcançam. (BURKE, 2004, p. 233).

Pela tríplice concepção de Buckland:

- Fotografia como Informação como Coisa $\rightarrow$ Objetos fotográficos (negativos de vidro e flexíveis, positivos em papel, diapositivos);

- Fotografia como Informação como Processo $\rightarrow$ a pesquisa histórica contextualizadora da imagem e sua correlação com outros documentos - fotográficos ou textuais ou outros quaisquer - na construção e/ou amplificação de sentido da imagem;

- Fotografia como Informação como Conhecimento $\rightarrow$ resultados de investigações e pesquisas de caráter comparativo entre fotografias e textos históricos. 
Annateresa Fabris, comentando as análises pré-fotográficas de Willian Ivins Jr. ${ }^{9}$, aponta:

A fotografia passa a desempenhar de imediato duas funções utilitárias dos processos gráficos: é uma fonte de notícias e um registro de documentos. Enquanto a primeira função não é prerrogativa exclusiva da fotografia, a segunda torna-se seu domínio privilegiado, pois só ela é capaz de fornecer um registro visual que possa ser usado como meio de estudo, de análise. (FABRIS, 2006, p. 158)

Saber observar - e saber ler - imagens fotográficas é resultado de muito exercício. Quem foi educado na primeira infância pela Caminho Suave (LIMA, 2010), uma cartilha de alfabetização pela imagem, sai ganhando nesta trilha não muito fácil - embora lúdica e prazerosa - que se espera nos leve à produção de sentidos através da leitura imagética.
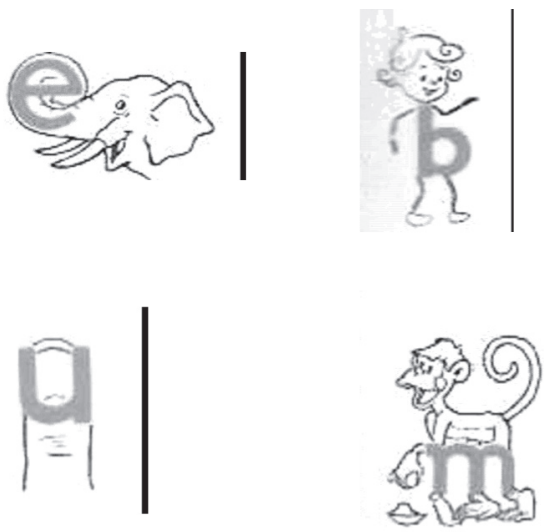

Fonte: LIMA, Branca A. Caminho suave (renovada e ampliada). São Paulo: Edipro, 2010.

Sabe-se que a leitura de fotografias demanda muitas lentes, a saber:

- É necessário conhecer alguns detalhes básicos de técnica fotográfica para se entender o mínimo do processo de produção de uma fotografia;
- É preciso ter algumas noções de processos fotográficos históricos - e isso já inclui a fotografia digital - para poder avaliar a data ou período em que a fotografia foi produzida (e, até, avaliar se uma imagem fotográfica sofreu adulteração física ou digital);

- É bom que se esteja imbuído de uma predisposição epistemológica que conduza a reflexões em torno do objeto fotográfico para, através dele e com ele, estabelecer relações com outras fontes de conhecimento e, assim, gerar, informação;

- É fundamental estabelecer minimante uma geografia da imagem e saber escolher a melhor direção para uma varredura que permita uma decupagem ampla e rica em detalhes para a promoção de mais dados informacionais sobre a fotografia;

- É desejável que se saiba reconhecer estilos, períodos, escolas e até fotógrafos numa mirada inicial da fotografia, o que certamente fornecerá um outro tanto de informações úteis.

Saber observar cuidadosa e lentamente uma imagem hoje em dia é muito difícil; isto soma um grau a mais de dificuldade às tarefas acima. Entretanto, é fundamental que se saiba ler uma fotografia antes de proceder à sua análise documentária.

\section{Conclusão}

A Ciência da Informação trabalha com representações; através de suas operações, conceitos representam documentos, termos representam textos escritos ou imagéticos (entre outros).

A fotografia, por sua vez, pode ser tida, também, como uma representação. Ela, enquanto recorte de espaço-tempo pode

\footnotetext{
9 IVINS Jr., W. M. Imagen impresa y conocimiento: análisis de la imagen prefotográfica. Barcelona: Gustavo Gili, 1975.
} 
ser tomada como parte da realidade, como representação do real. Entretanto, para isto concorrem as três categorias de Peirce e não apenas o índice. Ele mesmo já dizia que nenhuma de suas três categorias existe em estado puro e que cada uma se apóia nas outras, de uma ou de outra maneira.

A fotografia não é a mãe das imagens no que se refere à sua idade, mas com certeza é a matriarca das imagens técnicas. A possibilidade de copiar o real em pedaços de papel através da guilhotinada no tempo e no espaço, e o fato de conformar um dispositivo fotográfico físico (ótico) e, posteriormente, químico, relega à fotografia um papel revolucionário nas ciências, nas artes e na sociedade. O funcionamento de tal dispositivo fotográfico é constituído pela impressão, pelo registro visível de traços, tons, cores e outros detalhes que caracterizam a fotografia.

Segundo Schaeffer, no campo da materialidade do funcionamento do dispositivo fotográfico,

[...] a fotografia é uma impressão e, no âmbito semiótico, ela é um índice. Toda fotografia em igualmente impressão e índice [...]" (SCHAEFFER, 1996, p. 44-5).

Sua reprodutibilidade infinita trouxe possibilidades inumeráveis e as primeiras consequências disto já foram computadas por Benjamin (1987). Para além de ser embrião do cinema, a fotografia é o germe de várias outras transformações, perpassando a informática, a eletrônica, a computação e suas subáreas.

A promessa e o vaticínio de Baudelaire ${ }^{10}$ de que a fotografia serviria às ciências e às artes, e as infundadas opiniões de que ela substituiria a pintura são dois grandes marcos reativos - ou reacionários - à invenção da fotografia. Longe de ser substituta do pincel, do olho e da mão humana, a fotografia é, ao contrário, ponto de origem do desenvolvimento de outras técnicas, de vários setores artísticos e de inumeráveis aplicações científicas.

Após ser vista como uma quase-mágica da representação fiel do referente, provocando sentimentos inequívocos de admiração e se tornando objeto de desejo de todos que a ela podiam ter acesso, a fotografia vem mostrar seu caráter de registro e de documento (não ainda no sentido arquivístico), evidenciado no testemunho de um tempo-espaço, passível de ser utilizada como prova e já marcando indelevelmente seu espaço de/na memória.

Por tudo isso que caracteriza a fotografia como imagem, o tratamento informacional do documento fotográfico em acervos (seja em Arquivos, Bibliotecas, Centros de Documentação e Memória ou Museus) aponta para a necessidade de se conhecer processos fotográficos históricos (inclusive a fotografia digital), linguagem fotográfica e narrativa fotográfica, para melhor elaborar estruturas que conectem com mais acurácia a fotografia ao usuário de imagens.

\section{Referências}

BARTHES, Roland. A câmara clara; nota sobre a fotografia. Rio de Janeiro: Nova Fronteira, 1984.

BARTHES, Roland. O óbvio e o obtuso; ensaios críticos III. Rio de Janeiro: Nova Fronteira, 1990.

\footnotetext{
10 "Nesses dias deploráveis, uma nova indústria surgiu, que muito contribuiu para confirmar a tolice em sua fé... de que a arte é e não pode deixar de ser a reprodução exata da natureza... [...] Se for permitido à fotografia substituir a arte em algumas de suas funções, em breve ela a suplantará e corromperá completamente, graças à aliança natural que encontrará na tolice da multidão. É preciso, pois, que ela cumpra o seu verdadeiro dever, que é o de servir às ciências e às artes. Charles Baudelaire apud Benjamin, 1987, p. 107.
} 
BENJAMIN, Walter. A obra de arte na era de sua reprodutibilidade técnica, in Obras escolhidas; magia e técnica, arte e política. $3^{a}$ ed. São Paulo: Brasiliense, 1987, p. 165-196.

BUCKLAND, Michael K. Information as thing. In: Journal of the American Society of Information Science, v. 42, n. 5, p. 351-360, 1991.

BURKE, Peter. Testemunha ocular; História e imagem. Bauru: EDUSC, 2004. (Coleção História).

DUBOIS, Philippe. El acto fotografico: de la representación a la recepción. Barcelona: Paidós, 1986. (Paidós Comunicación, 20).

FABRIS, Annateresa. A imagem técnica: do fotográfico ao virtual, in FABRIS, A.; KERN, Maria Lúcia B. (org.s). Imagem e conhecimento. São Paulo: EDUSP, 2006, p. 157-178.

GUIMARÃES, César. O novo regime do visível e as imagens digitais. In: VAZ, Paulo B., NOVA, Vera C. (org.s). Estação imagem; desafios. Belo Horizonte: UFMG, 2002, p. 147-161.

HALBWACHS, Maurice. A memória coletiva. São Paulo: Centauro, 2004.
IZQUIERDO, Ivan. Memória. Porto Alegre: Artmed, 2002.

LIMA, Branca A. Caminho suave (renovada e ampliada). São Paulo: Edipro, 2010.

MANINI, Miriam P. Análise documentária de fotografias; um referencial de leitura de imagens fotográficas para fins documentários. São Paulo, 2002. Tese (doutorado) - Escola de Comunicações e Artes, USP.

MANINI, Miriam P. Leitura de informações imagéticas; ajustes ainda necessários ao "novo" paradigma. In: MANINI, Miriam P.; MARQUES. Otacílio G.; MUNIZ, Nancy C. (org.s). Imagem, memória e informação; Anais do Seminário Aberto do Grupo IMI. Brasília: Î́cone Gráfica e editora, 2010, p. 11-31.

PEIRCE, Charles S. Semiótica. $3^{a}$ ed. São Paulo: Perspectiva, 1999.

RICOEUR, Paul. A memória, a História, o esquecimento. Campinas: UNICAMP. 2007.

SCHAEFFER, Jean-Marie. A imagem precária; sobre o dispositivo fotográfico. Campinas: Papirus, 1996. (Campo Imagético). 
